\title{
Generic competitive strategies on organizational performance in Nepalese Commercial Banks
}

\author{
Jitendra Pd. Upadhyay, Ph.D. \\ Associate Professor, Nepal Commerce Campus, T. U. \\ Pitri Raj Adhikari \\ Lecturer, Shanker Dev Campus, T. U.
}

\begin{abstract}
This paper attempts to examine the impact of generic competitive strategy on organizational performance in Nepalese commercial banks. It has employed descriptive and causal comparative research design to estimate the relationship between dependent variable (organizational performance) with independent variables (differentiation strategy, cost leadership strategy, focus strategy, organization's core competency and bank size). Data has been collected from 384 respondents by using structured questionnaire. The multiple regression model has been used to test the relationship. It is found that organizational performance of banks are influenced by cost leadership, differentiation, focus, organization's core competency and bank size.
\end{abstract}

Key Words: Organizational performance, Cost leadership, Differentiation, Focus, Core competency, Size

Paper Type: Research Paper

\section{Introduction}

Organizational performance has attracted the interest of researchers and practitioners for the last few decades. Prior research has linked organizational performance with different generic competitive strategies. Performance is the accomplishment of a given task measured against preset standards of accuracy, completeness, cost and speed. In measuring a firm's performance generally one takes into account performance indicators such as sales, profits, cash flow, return on equity and growth (Dress \& Robinson, 1984). Similarly, Thompson et al. (2007) have argued that what enables a company to achieve or deliver better financial results from its operations is the achievement of strategic objectives that improve its competitiveness and market strength. Non-financial measures include innovativeness (Goldsmith et al., 1984) and market standing (Saunders et al., 1985; Hooley and Lynch, 1985). Therefore, performance is measured by both financial and non-financial measures. Porter (2000) stated that higher performance can be attained in a competitive industry through the pursuit of a generic strategy, that include development of an overall cost leadership strategy, differentiation strategy, or focus.

Strategic management is the formulation and implementation of the major goals and initiatives which has proven to be an important predictor of an increased organizational performance. The strategic practices have been linked to improving the overall performance of the firm (Dauda et al., 2010). Porter argued that superior performance can be achieved through pursuit of a competitive generic strategy. An identification 
and pursuit of the right competitive strategies is a source of superior performance to become a predominant priority in all organizations.

Cost leadership and differentiation are the two basic types of competitive advantage and performance norms vary significantly across strategic types. Acquaah and Ardekani (2008) stated firm implementing the combination of cost-leadership and differentiation strategy experiences substantial incremental performance benefits over using cost-leadership strategy only. However, the incremental performance benefits to firms implementing a combination strategy do not significantly differ from the performance of firms implementing only the differentiation strategy. Porter suggested that cost leadership, differentiation strategy and focus strategy are three fundamental ways in which firms might achieve sustainable competitive advantage.

Agha et al. (2012) examined that competitive advantage has significant positive impact on organizational performance. Core competency determines the degree of difference between average and superior performance. Core competency helps management to shape bank's market position by forecasting future (Godbout, 2000). There is a positive relationship between bank size and its performance (Adusei, 2015; Kioko, 2010; Makadok \& Walker, 2000)). However, Hirtle (2005) showed that there is no systematic relationship between bank size and overall performance. Haana et al.(2011) revealed that bank size reduces return volatility, the negative impact of bank size on bank earnings volatility decreases (in absolute terms) with market concentration and larger banks located in concentrated markets have experienced higher volatility.Gnyawali et al. (2008) found that while senior managers in many organizations have started to think and act strategically, they differ from the western model of strategic management. Much remains to be done in order for them to thoroughly understand and adopt the strategic management perspective so that they create advantages and outperform competitors in the global market. Therefore, it is suggested that high performing banks are more likely to pursue a combination of the generic strategies rather than pursuing one of the generic strategies in isolation (Thapa, 2010). The evidences show that the studies devoted to the impact of generic competitive strategies on the organizational performances of banks are of greater importance. Moreover, research has been done concerning to generic competitive strategies and performance in western context; however, there are few research have been done in Nepalese context. Hence, this paper attempts to examine the linkage between generic competitive strategies and performance of Nepalese commercial banks.

\section{Objective of the Study}

The main objective of the study is to analyze the relation between generic competitive strategies and organization performance of Nepalese commercial banks.

Other specific objectives are:

i. To analyze the impact of differentiation strategy and organizational performance.

ii. To analyze the impact of cost leadership and organizational performance.

iii. To analyze the impact of focus strategy and organizational performance.

iv. To analyze the impact of organization's core competency and organizational performance.

v. To analyze the impact of bank size and organizational performance.

\section{Operational Definitions and Hypotheses}

\section{Organizational Performance}

Organizational performance is a set of financial and nonfinancial indicators which offer information on the degree of achievement of objectives and results (Lebans \& Euske 2006). Organizational performance comprises the actual output or results of an organization as measured against its intended outputs. Similarly, Richard et al. (2009) stated that organizational performance encompasses three specific areas of firm outcomes: financial performance (profits, return on assets, return on investment, etc.); product market performance (sales, market share, etc.); and shareholder return (total shareholder return, economic 
value added, etc.).

\section{Differentiation}

A differentiation strategy is appropriate where the target customer segment is not price-sensitive, the market is competitive or saturated, customers have very specific needs which are possibly under-served, and the firm has unique resources and capabilities which enable it to satisfy these needs in ways that are difficult to copy. Aykan et al. (2013) found significant positive relationships between the differentiation strategy of competitive strategies and perceived qualitative-quantitative performances. Dess et al., (1984) also revealed the positive relationship between differentiation strategy and the organizational performance. Similarly, Atikiya et al. (2015) presented the significant positive relation between differentiation strategy and organizational performance. Based on it, this study develops the following hypothesis:

H1: There is a positive relationship between differentiation strategy and organizational performance.

\section{Cost leadership}

Cost leadership strategy involves the firm winning market share by appealing to cost-conscious or price-sensitive customers. This is achieved by having the lowest prices in the target market segment, or at least the lowest price to value ratio (price compared to what customers receive). It involves being the leader in terms of cost in industry or market. Kinyuira (2014) revealed that cost leadership strategy has a significant positive relationship with the organizational performance. Allen et al. (2006) stated that there is positive effect of generic strategies on optimal performance of organizations. Similarly, Atikiya et al. (2015) found that performance of an organization are significantly influenced by cost leadership strategy. Based on it, this paper develops the following hypothesis:

$\mathrm{H} 2$ : There is a positive relationship between cost leadership and organizational performance.

\section{Focus}

A marketing strategy, in which a company concentrates its resources on entering or expanding in a narrow market or industry segment is defined as a focus strategy. A focus strategy is usually employed where the company knows its segment and has products to competitively satisfy its needs. Allen et al. (2006) concluded there is positive and significant relationship between focus strategy and organizational performance. Generic strategies can successfully be linked to organizational performance through the use of focus strategy (Thompson et al., 2008; Datta, 2009). Therefore, the hypothesis can set as:

H3: There is a positive relationship between focus strategy and organizational performance.

\section{Core competency}

Core competency is a harmonized combination of multiple resources and skills that distinguish a firm in the marketplace and therefore are the foundation of companies' competitiveness. Zaim et al. (2013) argued that organizational performance is significantly influenced by the core competencies whereas Jabbouri et al. (2014) stated there is a significant correlation among core competences and organizational performance. Similarly, Nimsith et al. (2016) concluded significant impact of core competence on performance through competitive advantage. Based on it, the following hypothesis can set as:

H4: There is a positive relationship between organization's core competency and organizational performance.

\section{Bank Size}

Size represents the structure of a bank and it has influenced on the organizational performance through implying generic strategies. According to Kioko(2010), there is statistically significant relationship 
between bank size and organizational performance and Adusei (2015) concluded that increasing bank size leads to increasing organizational performance. Based on it, this paper develops the following hypothesis: H5: There is a positive relationship between bank size and organizational performance.

\section{Methods}

The descriptive research design has been used for searching the adequate data and information about factor affecting the organizational performance. Similarly, casual-comparative research design has also used to determine the casual or consequences of difference that already exist between the variables and the relationship between independent and dependent variables. Data are collected from 384 respondents through structured questionnaire survey and analyzed by using descriptive statistics and multi-step regression analysis. The model is presented as:

$$
\mathrm{OP}=\beta_{0}+\beta_{1} \mathrm{CLS}+\beta_{2} \mathrm{DIF}+\beta_{3} \mathrm{FCS}+\beta_{4} \mathrm{OCC}+\beta_{5} \mathrm{BSIZE}+\mathrm{e}_{\mathrm{it}}
$$

Where, $\mathrm{OP}=$ Organizational performance; $\mathrm{CLS}=$ Cost leadership;

$\mathrm{DIF}=$ Differentiation FCS= Focus; $\mathrm{OCC}=$ Organization's core competency;

$\mathrm{BSIZE}=$ Bank size; $\beta 1, \beta 2, \beta 3, \beta 4, \beta 5$ are the coefficient of the variables;

$\varepsilon=$ Error term.

\section{Validity and reliability}

In this study, Cronbach's alpha is used to test reliability of the primary data. The value of Cronbatch's alpha has obtained 0.896 which is greater than 0.7 which indicates there is strong internal consistency among the determinants of organizational performance.

\section{Results}

\section{Descriptive analysis}

The mean value of cost leadership strategy ranges from minimum of 3.33 to the maximum of 4.57 where weighted average mean value for the aspects of cost leadership strategy is 3.985 which indicate that aspects of the cost leadership strategy are satisfactory. The mean value of differentiation strategyranges from minimum of 3.22 to the maximum of 4.75 where weighted average mean value for the aspects of product quality is 3.83 which indicate that aspects of the differentiation strategy are satisfactory. The mean value of focus strategy ranges from minimum of 2.65 to the maximum of 4.33 where weighted average mean value for the aspects of focus strategy is 3.57 which indicate that an aspect of focus strategy is satisfactory.

The mean value of organizations core competency ranges from minimum of 3.71 to the maximum of 4.54 where weighted average mean value for the aspects of organizations core competency is 3.93 which indicate that aspects of organizations core competency are satisfactory. The mean value of banks size ranges from minimum of 3.89 to the maximum of 4.42 where weighted average mean value for the aspects of banks size is 4.07 which indicate that aspects of banks size are satisfactory. The mean value of organizational performance ranges from minimum of 3.43 to the maximum of 4.42 where weighted average mean value for the aspects of organizational performance is 3.99 which indicate that aspects of organizational performance are satisfactory.

\section{Correlation analysis}

The Pearson correlation coefficients have been conducted and the results are presented in Table 1

Table Pearson's correlation matrix for the impact of genetic competitive strategy on organizational performance in Nepalese Commercial Banks

This table shows the correlation between dependent variable i.e. organizational performance (OP) and independent variables i.e. cost leadership strategy (CLS), differentiation strategy (DIF), focus strategy 
(FCS), organizations core competency (OCC) and banks size (BSIZE).

\begin{tabular}{lcccccccc}
\hline Variables & Mean & S. D. & CLS & DIF & FCS & OCC & BSIZE & OP \\
\hline CLS & 3.9850 & .62762 & 1 & & & & & \\
DIF & 3.8300 & .64114 & $.491^{* *}$ & 1 & & & & \\
FCS & 3.5700 & .60160 & $.333^{* *}$ & $.201^{*}$ & 1 & & & \\
OCC & 3.9300 & .59743 & $.568^{* *}$ & $.551^{* *}$ & $.513^{* *}$ & 1 & & \\
BSIZE & 4.0700 & .57334 & $.489^{* *}$ & $.355^{*}$ & $.291^{* *}$ & $.452^{* *}$ & 1 & \\
OP & 3.9900 & .69259 & $.451^{* *}$ & $.397^{* *}$ & $.306^{* *}$ & $.517^{*}$ & $.411^{* *}$ & 1
\end{tabular}

Notes: The asterisk signs $(* *)$ and $(*)$ indicate that the results are significant at 1 percent and 5 percent level respectively.

The results present that there is positive relationship of all independent variables with organizational performance that indicates: better the cost leadership strategy, higher would be the organizational performance; higher the level of differentiation strategy, higher would be the organizational performance; more concentration in focus strategy leads to an increase in the organizational performance; stronger organization's core competency leads to improve the organizational performance of bank and larger banks size higher would be the organizational performance.

\section{Regression analysis}

Table 2

Regression result of generic competitive strategy on organizational performance.

This table represents the regression results on organizational performance (OP) i.e. dependent variable and independent variables i.e. cost leadership strategy (CLS), differentiation strategy (DIF), focus strategy (FCS), organizations core competency (OCC) and banks size (BSIZE). The regression results are estimated using regression equation as $\mathrm{OP}=\beta_{0}+\beta_{1} \mathrm{CLS}+\beta_{2} \mathrm{DIF}+\beta_{3} \mathrm{FCS}+\beta_{4} \mathrm{OCC}+\beta_{5} \mathrm{BSIZE}+\mathrm{e}_{\mathrm{it}}$

\begin{tabular}{|c|c|c|c|c|c|c|c|c|c|}
\hline \multirow{2}{*}{ Model } & \multirow{2}{*}{ Intercept } & \multicolumn{5}{|c|}{ Regression coefficients of } & \multirow{2}{*}{ Adj. $R^{2}$} & \multirow{2}{*}{ SEE } & \multirow{2}{*}{ F-value } \\
\hline & & CLS & DIF & FCS & OCC & BSIZE & & & \\
\hline \multirow{2}{*}{1} & 1.479 & 0.613 & & & \multirow{2}{*}{0.292} & \multirow{2}{*}{0.582} & \multirow{2}{*}{41.968} & & \\
\hline & $(4.029)^{* *}$ & $(6.481)^{* *}$ & & & & & & & \\
\hline \multirow{2}{*}{2} & 2.249 & & 0.431 & & \multirow{2}{*}{0.151} & \multirow{2}{*}{0.642} & \multirow{2}{*}{18.177} & & \\
\hline & $(5.947)^{* *}$ & & $(4.263)^{* *}$ & & & & & & \\
\hline \multirow{2}{*}{3} & 2.609 & & & 0.352 & \multirow{2}{*}{0.087} & \multirow{2}{*}{0.666} & \multirow{2}{*}{10.191} & & \\
\hline & $(6.658)^{* *}$ & & & $(3.188)^{* *}$ & & & & & \\
\hline \multirow{2}{*}{4} & 1.538 & & & & \multirow{12}{*}{$\begin{array}{c}0.597 \\
(5.963)^{* *}\end{array}$} & 0261 & 0507 & 35545 & \\
\hline & $(3.961)^{* *}$ & & & & & 0.261 & 0.591 & 35.545 & \multirow{3}{*}{20.205} \\
\hline \multirow{2}{*}{5} & 1.902 & & & & & 0.494 & \multirow{2}{*}{0.163} & \multirow{2}{*}{0.633} & \\
\hline & $(4.347)^{* *}$ & & & & & $(4.494)^{* *}$ & & & \\
\hline \multirow{2}{*}{6} & 1.172 & 0.519 & 0.181 & & & \multirow{2}{*}{0.307} & \multirow{2}{*}{0.578} & \multirow{2}{*}{22.867} & \\
\hline & $(2.878)^{* *}$ & $(4.836)^{* *}$ & $(1.711)$ & & & & & & \\
\hline \multirow{2}{*}{7} & 1.490 & & 0.376 & 0.271 & & & \multirow{2}{*}{0.195} & \multirow{2}{*}{0.622} & \multirow{2}{*}{12.930} \\
\hline & $(3.149)^{* *}$ & & $(3.778)^{* *}$ & $(2.578)^{* *}$ & & & & & \\
\hline \multirow{2}{*}{8} & 1.121 & 0.559 & & 0.159 & & & \multirow{2}{*}{0.307} & 0577 & 22570 \\
\hline & $(2.592)^{* *}$ & $(5.636)^{* *}$ & & $(1.586)$ & & & & 0.511 & $22.5 / 0$ \\
\hline 0 & 0.837 & 0.477 & 0.169 & 0.157 & & & 0313 & 0575 & 16231 \\
\hline 9 & $(1.809)$ & $(4.271)^{* *}$ & $(1.653)$ & $(1.539)$ & & & 0.315 & $0.5 / 5$ & 16.231 \\
\hline
\end{tabular}




\begin{tabular}{lccccccccc}
10 & 0.803 & 0.403 & 0.69 & & 0.321 & & 0.347 & 0.561 & 18.397 \\
& $(1.907)$ & $(3.506)^{* *}$ & $(0.639)$ & & $(2.602)^{* *}$ & & & & \\
11 & 0.790 & 0.443 & 0.148 & & & 0.201 & 0.318 & 0.572 & 16.578 \\
& $(1.713)$ & $(3.820)^{* *}$ & $(1.450)$ & & & $(1.743)$ & & & \\
12 & 0.541 & 0.411 & 0.150 & 0.131 & & 0.181 & 0.322 & 0.572 & 12.940 \\
& $(1.099)$ & $(3.496)^{* *}$ & $(1.423)$ & $(1.287)$ & & $(1.541)$ & & & \\
13 & 0.499 & 0.347 & 0.68 & 0.42 & 0.264 & 0.142 & 0.345 & 0.562 & 11.369 \\
& $(1.015)$ & $(2.927)^{* *}$ & $(0.605)$ & $(0.386)$ & $(1.907)$ & $(1.247)$ & & & \\
\hline
\end{tabular}

The asterisk signs $(* *)$ and $\left(^{*}\right)$ indicate that coefficients are significant at 1 percent and 5 percent levels.

The results show that beta coefficients are positive and significant for cost leadership strategy with the organizational performance. It reveals that cost leadership strategy has positive impact on the organizational performance of bank and this result is consistent to the finding of Atikiya et al. (2015). The beta coefficients are positive and significant for differentiation strategy which indicates that differentiation strategy has positive influence on the organizational performance of bank and it is similar to the study of Aykan et al. (2013). Similarly, the result presents that beta coefficient is positive and significant for focus strategy which indicates that the focus strategy has positive effect on the organization performance of bank. The result is similar to the finding of Thompson et al., (2008).

Likewise, the results also exhibit that the beta coefficients are positive and significant for organizations core competency with organizational performance which indicates that the organizations core competency has positive effect on the organizational performance of bank. The finding is similar to findings of Zaim et al. (2013). Additionally, beta coefficients are positive and significant for banks size. It states that larger the banks size, higher would be the organizational performance of bank. Thus, the finding is consistent with Kioko (2010).

\section{Conclusion}

Performance is measured by both financial and non-financial measures. Performance can be attained in a competitive industry through the pursuit of a generic strategy, that include development of an overall cost leadership strategy, differentiation strategy and focus.This study concludes that the organizational performance of Nepalese commercial banks are influenced by factors i.e. cost leadership, differentiation, focus, organization's core competency and bank size.

\section{References}

Atikiya, R., Mukulu, E.,Kihoro, J. and Waiganjo, E. (2015). Effect of cost leadership strategy on the performance of manufacturindifferent $\mathrm{g}$ firms in Kenya. The Strategic Journal of Business and Change Management, Vol. 2 (8), pp 134-143.

Acquaah, M., and Ardekani, M., (2008). Does the implementation of a combination competitive strategy yield incremental performance benefits? A new perspective from a transition economy in Sub-Saharan Africa. Journal of Business Research, 61(4), 346-354.

Agha, S., Alrubaiee, L., and Jamhour, M., (2011). Effect of core competence on competitive advantage and organizational performance. International Journal of Business and Management, 7(1), 192.

Allen, R. S., and Helms, M. M. (2006). Linking strategic practices and organizational performance to Porter's generic strategies. Business Process Management Journal, 12(4), 433-454.

Hirtle, B. (2005). The Impact of Network Size on Bank Branch Performance. New York.

Jabbouri, N. I. and Zahari, I. (2014). The role of core competencies on organizational performance: An empirical study in the Iraqi private banking sector ON. European Scientific Journal, 10(10), 130-139.

Kinyuira, D. (2014). Effects of Porter's Generic Competitive Strategies on the Performance of Savings and 
Credit Cooperatives (Saccos) in Murang'a County, Keny. IOSR Journal of Business and Management (IOSR-JBM), 93-105.

Koiko, N. P. (2010). THE RELATIONSHIP BETWEEN FIRM SIZE AND FINANCIAL. Africa: University of Nairobi.

Miller, A. and Dess, G.G., (1993). Assessing Porter's model in terms of generalizability, accuracy and simplicity. Journal of Management Studies, 30(4), 535-585.

Godbout, A. J. (2000). Managing core competencies: the impact of knowledge management on human resources practices in leading-edge organizations. Knowledge and Process Management, 7(2), 76.

Makadok, R., and Walker, G., (2000). Identifying a distinctive competence: Forecasting ability in the money fund industry. Strategic Management Journal, 21(8)853-864.

Zaim, H., Yasar, M. F., and Unal, O. F. (2013). Analyzing the effects of individual competencies on performance: A field study in services industries in Turkey. Journal of Global Strategic Management, 2(7), 67-77. 
